\title{
Beyond disclosure: Managing conflicts of interest to strengthen trust in our profession
}

Martin F. McKneally, MD

From the Department of Surgery, University of Toronto, Toronto, Ontario, Canada.

M.M. reports equity ownership in Johnson \& Johnson and Merck.

Received for publication Sept 7, 2006; Accepted for publication Oct 6, 2006.

Address for reprints: Martin F. McKneally, MD, Department of Surgery, University of Toronto, 77 Forest Grove Dr, Toronto, Ontario M2K 1Z4, Canada (E-mail: martin.mckneally@utoronto.ca; dmckneally@ sympatico.ca)

J Thorac Cardiovasc Surg 2007;133:300-2

$0022-5223 / \$ 32.00$

Copyright (C) 2007 by The American Association for Thoracic Surgery

doi:10.1016/j.jtcvs.2006.10.005
$\mathrm{C}$ ardiothoracic surgeons have competing personal and professional interests that we balance skillfully every day with our obligations to our families, our patients, our partners, and our institutions. Our financial interests in the volatile market of technological innovations have gained recent public attention, as surgeons and institutions participate in the invention and introduction of medical devices. ${ }^{1}$ In this editorial, I will try to outline the ethical foundations of our profession's approach to financial interests and make some suggestions about their management when they conflict with our professional obligations.

Trust binds civil society together. We trust others to deal with us with respect, honesty, and fairness, and we trust them more each time they do so. In a perfect world, we might rely on virtue alone to ensure honesty and fairness. In our imperfect world, standards of conduct and role-specific obligations are defined and legally enforced for those who are entrusted with superior knowledge, power, or authority over others, for example, physicians, scientists, lawyers, government officials, police, and overseers of institutions like hospitals and universities.

Members of our profession are trusted because we maintain high standards. The ethics of surgery - the values and principles that guide us - can be summarized in one word: trustworthiness. We are justifiably trusted to be technically competent and tirelessly committed to assuring that our patients receive the best care we can provide. In the fee-for-service system, we manage the inherent conflict between our financial incentive to perform operations and the interests of patients who may be best served by nonoperative treatment. Almost unconsciously, we follow a welldeveloped code of virtuous conduct ingrained during residency and reinforced by collegial standards and community respect.

We try to report our clinical and research results honestly, giving an unbiased account to help other practitioners and researchers improve on current approaches to the difficult problems we diagnose and treat. Researchers are held to a high standard of unbiased communication because science is built on the foundation of publicly reported results of their investigations. The standard is enforced by peer and public review. Deliberate deception leads to public and professional disgrace. The false claim by South Korean researcher Hwang Woo-suk-that he created new patientspecific stem cell lines-is a vivid recent example of betrayal of society's trust. His interest in personal and professional advancement (which was temporarily spectacular) led to an unethical breach of his obligation as a scientist to conduct and report reliable research fully and honestly.

Sometimes false or misleading assertions are not the result of deliberate decisions to deceive. They may arise from unconscious bias in our interpretation of the facts as we see them. The lens through which we see our data can be distorted by strong but unrecognized elements of belief, hope, self-deception, or self-interest. Our biases can influence our perceptions.

\section{Conflicts of Interests}

When personal or private interests in advancement, profit, or other advantages might interfere with a publicly recognized professional obligation, the situation is defined as a conflict of interest (COI). ${ }^{2}$ The existence of a COI is not necessarily culpable or harmful, but it requires management to prevent interference, or the perception of interference, with a professional obligation. 


\section{Managing COls}

COIs are managed by disclosure, mediation by an objective third party, or various forms of prohibition. ${ }^{3}$ The minimum standard of management of COI is voluntary disclosure of the situation - warning the public or particular vulnerable persons, such as our patients, of our potential bias. Mediation and prohibition are progressively more stringent measures.

Disclosure. Disclosure is generally accepted as adequate management of minimal conflicts. Disclosure is also accepted widely as an appropriate procedure when more serious conflicts arise. We currently accept disclosure as a sufficient form of COI management in our professional meetings and publications. Although intended to provide transparency, disclosure leaves analysis of the magnitude and impact of bias to the listener or reader to decode. The discloser, who could explain the conflict and clarify its management, can obscure or leave unspecified the extent of the conflict, for example, the involvement of a commercial sponsor in the control of data or the analysis and interpretation of results. Semitransparent statements that an author "has a financial relationship" with a manufacturer or institution whose interests will benefit from a positive report are commonly accepted but insufficient explanations of management of COI.

Mediation. Mediation by an independent third party is a more effective and publicly defensible level of management of COI. The reference standard exemplifying this approach is the management of equity shares held in industries that do business with government. When an industry leader is appointed to government service, the appointee's shares are transferred to an independent trust fund managed without interference from the potentially conflicted official. This reduces the risk or appearance that decisions made on behalf of the public will be influenced by the financial interests of the appointee.

In medicine, ownership of equity shares in a company that manufactures a device or drug may bias practitioners' judgments about prescribing the product for their patients or describing its effectiveness in a research report. Highly publicized problems with investigators' and institutions' equity ownership, for example, of gene transfer technology in the tragic case of Jesse Gelsinger, ${ }^{*}{ }^{4}$ have led to the introduction of COI committees at many universities, hospitals, and clinics. These committees provide advice and guidance through institutionally mandated policies on management of conflicts. A substantial organization of highly qualified participants in COI committees in the United States-the Forum on Conflict of Interest in Academe, which is affiliated with the Association of American Med-

*Jesse died of a massive systemic inflammatory response after receiving the ornithine transcarbamylase gene delivered through an adenovirus vector. Undisclosed lethal toxicity in animal studies and deviation from the treatment protocol were linked to his physician's financial interests in the vector, sold shortly afterward for $\$ 13.5$ million USD. ical Colleges-meets annually and converses actively online to share ideas about management of COIs (personal communication from Julie Gottlieb, 2006).

Institutional review boards and research ethics boards have been asked to mediate or advise on COI at some institutions. Their focus on patient protection and consent makes this seem a logical extension of their responsibilities. However, these boards are generally overstretched, and the financial details of COI management are complex. For these reasons, institutional COI committees are proving to be a more effective solution. COI management by mediation is implemented by impartial data managers, statistical analysts, safety monitoring boards, review committees, editors, and peer reviewers.

Prohibition. Prohibition is the most severe and definitive form of COI management. Some conflicts are so substantial that prohibition or abstention is required. For example, judges avoid the appearance of bias by recusing themselves from legal cases involving their relatives, associates, or business interests. For similar reasons, some medical journals prohibit editors and authors of review articles from owning stock or retaining financial relationships with companies whose value might be enhanced by favorable reports in the journal. This requirement has become increasingly problematical, because many prominent academic physicians and scientists have financial relationships with industry. Understandably, these relationships are strongly encouraged by industry to ensure the input of leading researchers and scholars into the quest for innovative and patentable devices, drugs, and treatments. Some view this as a vicious cycle of increasing compromise of scientific integrity. Others see a virtuous cycle in which industrial partners provide the capacity for production, evaluation, and distribution of new technology that could not be achieved without their help. ${ }^{5}$ This is the rationale for institutional collaboration with industry and venture capital in biotechnical startup companies within our universities and hospitals. I favor the virtuous cycle view, if it is well managed. In contrast, Bob Sade, chairman of the Ethics Committee of The American Association for Thoracic Surgery, has argued that the best way to protect our professional integrity is to avoid business entanglements entirely. ${ }^{6}$

\section{How We Manage COI in the Journal}

The Journal's ethical and legal obligation is to provide reliable information and advice to subscribers and readers, a diverse group that includes practitioners, researchers, and students of cardiothoracic surgery. To manage potential conflicts with this obligation, our editors and editorial board regularly disclose their financial interests and recuse themselves from review of submissions whose authors, institutions of origin, sponsors, or topic might bias their judgment in the decision to publish. Guest reviewers similarly recuse 
themselves where conflicts might bias their advice. Authors are required to list their commercial interests (fees, salary, equity, grant support, patents) on a standard form as a condition of publication. After acceptance of a manuscript, the interests that are judged relevant to the work are published on the title page of the article. If questions arise, they are referred to the corresponding author for clarification. A small Journal ethics committee adjudicates problems that remain; its members are Jim Jones, Martin McKneally, Bob Sade, and Dick Sanderson.

We are still at the same stage of cumbersome detailed language of disclosure that all journals currently employ. Clear definitions and consensus on practice will eventually emerge, as they did with independent ethics review of research practices and animal care. We now have such a clear and widespread understanding of the policies and procedures of research ethics and animal care committees that we accept the shorthand of a reference to their approval as evidence of adequate management without detailed explanations. A clear and equally concise explanation will evolve as COI committees develop uniform standards. I am confident that progress toward this goal will be catalyzed by the help of our readers, our ethics committees, and the members of our profession. In the interim, authors with COI can strengthen the trustworthiness of their reports by describing their management of conflicts in the Discussion section of their articles, just as they currently describe the limitations of their studies. These clarifications help readers and listeners put the findings and interpretations in perspective and evaluate how well the authors managed the influence of potential sources of bias as they developed, analyzed, and reported their data.

I am grateful to Bob Sade, Dick Sanderson, and Deborah McKneally for helpful comments on earlier versions of this editorial.

\section{References}

1. Wechsler AS. Conflict of interest: What's a journal to do? J Thorac Cardiovasc Surg. 2006;131:771-2.

2. Khushf G, Gifford R. Understanding, assessing, and managing conflicts of interest. In: McCullough LB, Jones JW, Brody BA, editors: Surgical ethics. New York: Oxford University Press; 1998. p. 342-66.

3. Thompson DF. Understanding financial conflicts of interest. $\mathrm{N} \mathrm{Engl}$ J Med. 1993;329:573-6.

4. Savulescu J. Harm, ethics committees and the gene therapy death. J Med Eth. 2001;27:148-50.

5. Stossel TP. Regulating academic-industrial research relationshipssolving problems or stifling progress? N Engl J Med. 2005;353:1060-5.

6. Sade RM. Profits and professionalism. J Thorac Cardiovasc Surg. 2002;123:403-5. 